Article

\title{
Synthesis, Structure, and Dielectric Properties of (3-Nitroanilinium) (18-Crown) $\left(\mathrm{PF}_{6}\right)$
}

\author{
Le Wang, Liu-lei Qin, Yang Liu *, Peng Wang, Hui-ting Xu and Zun-qi Liu * \\ College of Chemical Engineering, Xinjiang Agricultural University, Urumqi 830052, China; \\ wangle305@126.com (L.W.); liuleiqin@126.com (L.-1.Q.); wangpeng202109@126.com (P.W.); \\ xht199412@163.com (H.-t.X.) \\ * Correspondence: liuyangxj85@163.com (Y.L.); lzq@xjau.edu.cn (Z.-q.L.); Tel.: +86-991-876-2118 (Z.-q.L.)
}

Received: 9 October 2020; Accepted: 4 November 2020; Published: 11 November 2020

\begin{abstract}
Nitroanilinium) (18-crown) $\left(\mathrm{PF}_{6}\right)(\mathbf{1})$, which is an organic-inorganic hybrid containing one-dimensional chains of hydrogen-bonded supramolecular cations, was synthesized under slow evaporation conditions and subjected to differential scanning calorimetry, temperature-dependent dielectric measurements, and variable-temperature single-crystal X-ray diffraction analysis. These analyses revealed the occurrence of a reversible structural phase transition [P21/n $P 21 / \mathrm{c}]$ at $223 \mathrm{~K}$ and a dielectric anomaly, which, based on the results of structural analysis and potential energy calculations, was attributed to the synergistic effect between the pendulum-like motion of the nitro group in the supramolecular cation, (3-nitroanilinium)(18-crown), and the order-disorder motion of $\mathrm{PF}_{6}{ }^{-}$anions.
\end{abstract}

Keywords: structural phase transition; pendulum-like motion; order-disorder motion; dielectric anomaly

\section{Introduction}

Supramolecular assemblies constructed from inorganic and organic building blocks (ionic or molecular) have become important for the fields of host-guest chemistry and the theoretical modeling of structure-property relationships [1-5]. Novel organic-inorganic hybrid complexes have the potential of combining the distinct properties of their components and, therefore, exhibit appealing features (e.g., dielectric anisotropy, uniaxial polarity ferroelectricity, and strongly non-linear properties) and diverse structures (e.g., zero-dimensional molecular motors, one-dimensional chains, two-dimensional layers, and three-dimensional networks) [6-10]. From the viewpoint of crystal engineering, the assembly of molecular complexes with motional or flexible components is an effective and rational strategy [11-16].

Crown-type ethers containing $\mathrm{S}$ or $\mathrm{O}$ heteroatoms as acceptors can effectively bind cations $\left(\mathrm{Na}^{+}\right.$, $\mathrm{K}^{+}, \mathrm{Ba}^{2+}, \mathrm{H}_{3} \mathrm{O}^{+}, \mathrm{RNH}_{3}{ }^{+}$, etc.) via covalent coordination bonding or weak hydrogen bonding and are widely used in supramolecular chemistry because of their appealing structural features, phase transitions, and thermochromic behavior. Crown ethers containing repeating $-\mathrm{OCH}_{2} \mathrm{CH}_{2} \mathrm{O}-$ units exhibit high flexibility, i.e., can adopt different shapes [17-23]. Therefore, cavity size and shape control is expected to allow the development of macrocycles capable of specifically recognizing certain guest molecules [24-29]. For example, the combination of 18-crown-6 with $\mathrm{Ar}-\mathrm{NH}_{3}{ }^{+}$guests in a 1:1 stoichiometry affords $\left[\left(\mathrm{Ar}-\mathrm{NH}_{3}\right) \cdot(18 \text {-crown-6) }]^{+}\right.$supramolecular cation units in which the $\mathrm{Ar}-\mathrm{NH}_{3}{ }^{+}$ bond is almost perpendicular to the mean plane of the crown ether ring, which allows the cation to freely rotate in the crown ether cavity and may result in dielectric anomalies and structural phase transitions. Moreover, the multi-component $\left[\left(\mathrm{Ar}-\mathrm{NH}_{3}\right) \cdot(18 \text {-crown-6) }]^{+}\right.$unit allows for various cation/anion and order-disorder motions in the crystal structure that significantly change the conductive, magnetic, 
and dielectric properties of the bulk [30-33]. For example, the synergistic disordering of cations and anions triggers dielectric anisotropy and phase transitions in [Hcpa(18-crown-6)] $\left[\mathrm{ClO}_{4}\right]$ crystals. In this case, molecular motion leads to sequential reversible phase transitions, thermal anomalies, and abrupt dielectric anomalies during heating and cooling [34]. Previously, we showed that the 3-nitroanilinium cation forms an $\mathrm{N}-\mathrm{H} \cdots \mathrm{O}$ hydrogen bond with the oxygen atom of 18-crown-6 in [(3-nitroanilinium)(18-crown-6)][ $\left[\mathrm{IO}_{4}\right]\left(\mathrm{CH}_{3} \mathrm{OH}\right)$, revealing that the order-disorder rotation of $\mathrm{CH}_{3} \mathrm{OH}$ results in a dielectric anomaly and a phase transition at $220 \mathrm{~K}$ [35]. Herein, we build on the results of our previous work and report (3-nitroanilinium) (18-crown) $\left(\mathrm{PF}_{6}\right)(\mathbf{1})$, which contains one-dimensional hydrogen-bond chains and exhibits a phase transition and a dielectric anomaly originating from the pendulum-like motion of nitro groups and the order-disorder motion of $\mathrm{PF}_{6}{ }^{-}$anions. Moreover, the synthesis of $\mathbf{1}$ as well as the results of its analysis by variable-temperature single-crystal X-ray diffraction, infrared (IR) spectroscopy, differential scanning calorimetry (DSC), and dielectric property measurements are discussed in detail.

\section{Results and Discussion}

\subsection{IR Spectroscopic Analysis}

The IR spectrum of 1 (Figure S1) featured peaks at 1527.62, 1471.68, 1354.08, and $1288.49 \mathrm{~cm}^{-1}$, ascribed to the skeletal vibration of the aromatic ring, a strong broad band between 3273.20 and $2808.36 \mathrm{~cm}^{-1}$ assigned to the intermolecular $\mathrm{N}-\mathrm{H} \cdot \mathrm{O}$ hydrogen bonds between $-\mathrm{NH}_{3}{ }^{+}$and $-\mathrm{NO}_{2}$ groups, and peaks between 931.61 and $754.16 \mathrm{~cm}^{-1}$ attributed to $\mathrm{P}-\mathrm{F}$ stretching vibrations of $\mathrm{PF}_{6}{ }^{-}$. The characteristic peaks of the -O-C-C- units of 18 -crown-6 were located at 1093.63, 960.55, and $842.89 \mathrm{~cm}^{-1}$. Thus, IR spectroscopy confirmed the presence of three components (18-crown-6, 3-nitroanilinium cation, and $\mathrm{PF}_{6}{ }^{-}$anion) in crystalline 1.

\subsection{Hermogravimetric (TG) and DSC Analyses}

The thermal stability of $\mathbf{1}$ was probed by TG and DTA measurements in the range of 300-890 K (Figure S2). The DTA curve showed a weak endothermic peak at $355.4 \mathrm{~K}$ and a sharp endothermic peak at $455.6 \mathrm{~K}$ corresponding to the melting point of $\mathbf{1}$. Thus, $\mathbf{1}$ was concluded to be stable at temperatures below its melting point and was additionally characterized by DSC, as this technique can effectively detect reversible phase transitions occurring upon heating and cooling. The DSC curve of 1 revealed the occurrence of a reversible phase transition at $\sim 211.2 \mathrm{~K}$ and $\sim 215.3 \mathrm{~K}$ in the cooling mode and around 218.4 $\mathrm{K}$ and $223.7 \mathrm{~K}$ in the heating mode (thermal hysteresis = 7.2 $\mathrm{K}$ and $8.4 \mathrm{~K}$, Figure 1), suggesting that this transition was of a second-order type, according to the broad peaks with narrow thermal hysteresis. The total transition enthalpy $\Delta H$ equaled $297.12 \mathrm{~J} / \mathrm{mol}$ in the cooling mode and $259.93 \mathrm{~J} / \mathrm{mol}$ in the heating mode. The entropy change was estimated as $\Delta S=\Delta H / T_{\mathrm{c}}=1.38$ and $1.16 \mathrm{~J} /(\mathrm{mol} \mathrm{K})$ for both the cooling and heating runs. On the basis of the Boltzmann equation, $\Delta S=R \ln N$, where $R$ is the universal gas constant, the ratio of the numbers of respective geometrically distinguishable orientations $(N)$ was obtained as 1.18 and 1.15. The fact that the values were close to unity suggests that the phase transition involved proton transfer or dominant molecular movement accompanying the order-disorder transition. 


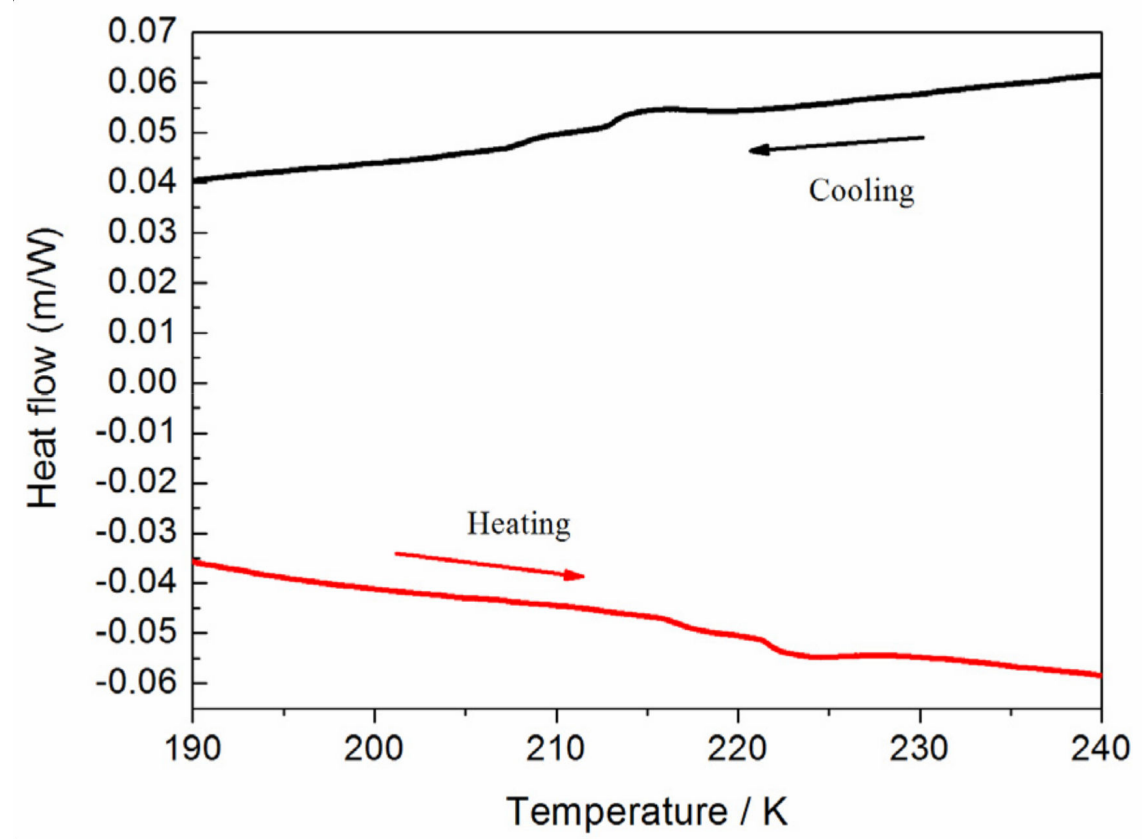

Figure 1. Differential scanning calorimetry curves of 1 recorded upon heating and cooling.

\subsection{Crystal Structure Analysis}

The above phase transition was further characterized by single-crystal X-ray analysis of 1 at $128 \mathrm{~K}$ (low-temperature phase, LTP) and $293 \mathrm{~K}$ (room-temperature phase or RTP) (Table 1). The RTP was found to crystallize in a monoclinic crystal system with a centrosymmetric space group of $P 21 / c$ and cell parameters of $a=13.9331(12) \AA, b=13.0960(12) \AA, c=15.1576(13) \AA, \alpha=90.00^{\circ}, \beta=116.884(2)^{\circ}$, $\gamma=90.00^{\circ}, V=2466.9(4)$, and $Z=4$. The RTP asymmetric unit contained one 3-nitroanilinium cation, one 18-crown-6 molecule, and one $\mathrm{PF}_{6}{ }^{-}$anion. Furthermore, one $\mathrm{PF}_{6}{ }^{-}$anion remained disordered over two staggered orientations and occupied two sites, namely F1, F2, F3, F4, F5, and F6 and F1A, F2A, F3A, F4A, F5A, and F6A (Figure 2a). The occupation factors of F and FA sites ( 0.643 and 0.357 , respectively) suggested that, in the RTP, the $\mathrm{PF}_{6}{ }^{-}$anion underwent disordered rotation about the central $\mathrm{P}$ atom, which could possibly result in energy change and electrical property abnormalities. Similarly to the RTP, the LTP crystallized in the monoclinic system but belonged to a different space group, $P 21 / n$, featuring $a=13.7283(12) \AA, b=12.9198(12) \AA, c=15.3220(18) \AA, \alpha=90.00^{\circ}, \beta=116.314(2)^{\circ}, \gamma=90.00^{\circ}$, $V=2436.0(4)$, and $Z=4$. The slight change of $b, \alpha$, and $\gamma$ upon going from the RTP to the LTP was ascribed to the effect of thermal contraction. However, much larger changes were concomitantly observed for $a$ (decrease of $\sim 1.49 \%$ ), $c$ (increase of $\sim 1.08 \%$ ), $\beta$ (decrease of $\sim 0.489 \%$ ), and $V$ (decrease of $\sim 1.27 \%$ ). Similarly to that of the RTP, the asymmetric unit of the LTP contained one 18-crown- 6 molecule, one 3-nitroanilinium cation, and one $\mathrm{PF}_{6}{ }^{-}$anion (Figure $2 \mathrm{~b}$ ). However, the phenomenon of the $\mathrm{PF}_{6}{ }^{-}$disorder was not observed for the LTP, which suggested that the reversible LTP to RTP transition is caused by the order-disorder transition of the above anion.

$$
[\mathrm{a}]: \mathrm{R}=\sum\left(\left|F_{o}\right|-\left|F_{c}\right|\right) / \sum\left|F_{a}\right|[\mathrm{b}]: R_{W}^{2}=\sum_{w}\left(F_{o}^{2}-F_{c}^{2}\right)^{2} / \sum_{w}\left(F_{o}^{2}\right)^{2}
$$


Table 1. Crystallographic data for $\mathbf{1}$ at $128 \mathrm{~K}$ and $293 \mathrm{~K}$.

\begin{tabular}{ccc}
\hline Temperature & $\mathbf{1 2 8} \mathbf{K}$ & $\mathbf{2 9 3 \mathbf { K }}$ \\
\hline Chemical formula & $\mathrm{C}_{18} \mathrm{H}_{31} \mathrm{~F}_{6} \mathrm{~N}_{2} \mathrm{O}_{8} \mathrm{P}$ & $\mathrm{C}_{18} \mathrm{H}_{31} \mathrm{~F}_{6} \mathrm{~N}_{2} \mathrm{O}_{8} \mathrm{P}$ \\
Formula weight & 548.41 & 548.41 \\
Crystal size $\left(\mathrm{mm}^{3}\right)$ & $0.43 \times 0.31 \times 0.16$ & $0.313 \times 0.248 \times 0.116$ \\
Crystal system & monoclinic & monoclinic \\
Space group & $P 2_{1} / \mathrm{n}$ & $P 2_{1} / \mathrm{c}$ \\
$a(\AA)$ & $13.7283(12)$ & $13.9331(12)$ \\
$b(\AA)$ & $12.9198(12)$ & $13.0960(12)$ \\
$c(\AA)$ & $15.3220(18)$ & $15.1576(13)$ \\
$\alpha\left(^{\circ}\right)$ & 90.00 & 90.00 \\
$\beta\left(^{\circ}\right)$ & $116.314(2)$ & $116.884(2)$ \\
$\gamma\left({ }^{\circ}\right)$ & 90.00 & 90.00 \\
$V\left(\AA^{3}\right)$ & $2436.0(4)$ & $2466.9(4)$ \\
$Z$ & 4 & 4 \\
$D_{\text {calc }}\left(\mathrm{g}^{\circ} \cdot \mathrm{cm}^{-1}\right)$ & 1.490 & 1.474 \\
$F(000)$ & 1136 & 1140 \\
$\mu \mu\left(\mathrm{mm}^{-1}\right)$ & 0.204 & 0.202 \\
$R_{\text {int }}$ & $0.960-25.00$ & $0.999-25.242$ \\
$R(I>2 \sigma(I))[\mathrm{a}]$ & 0.0996 & 0.0783 \\
$\mathrm{~W}^{\circ} R($ all data) $[\mathrm{b}]$ & 0.1205 & 0.1044 \\
$\mathrm{GOF}$ & 0.2926 & 0.1951 \\
& 1.004 & 1.064 \\
\hline
\end{tabular}

(a)

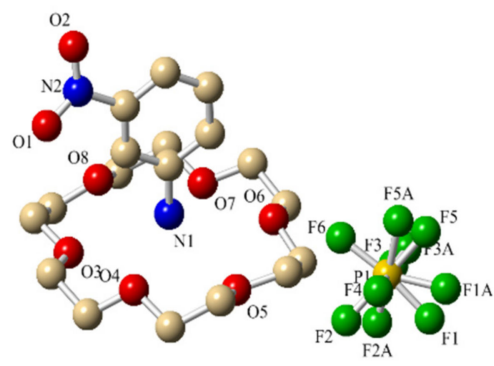

(b)

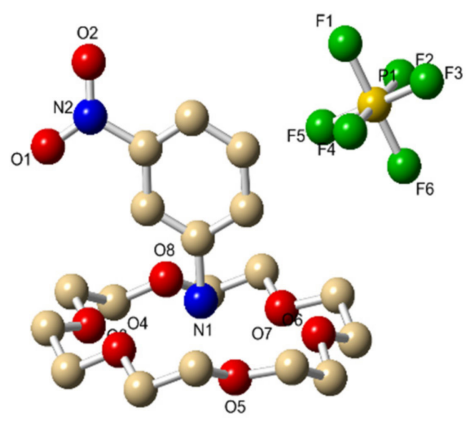

Figure 2. Asymmetric crystal structures of (a) the room-temperature phase and (b) the low-temperature phase of 1 .

The molecules of 18 -crown-6 had a nearly ideal conformation with a close to- $D_{3 \mathrm{~d}}$ symmetry, and the six oxygen atoms of the crown ring were alternately located above and below its median plane, forming two approximately parallel and nearly equilateral triangles. The dihedral angles between the upper-oxygen-atom $(\mathrm{O} 3, \mathrm{O} 5, \mathrm{O} 7)$ and lower-oxygen-atom $(\mathrm{O} 4, \mathrm{O} 6, \mathrm{O} 8)$ planes equaled $0.60^{\circ}$ and $0.48^{\circ}$ for the RTP and LTP, respectively, and indicated a small twist in the crown conformation. The 3-nitroanilinium cation was connected to the 18-crown-6 molecule via intermolecular $\mathrm{N}-\mathrm{H} \cdot \mathrm{O}$ hydrogen bonds between the 3-nitroanilinium nitrogen and 18-crown-6 oxygens to form a supramolecular rotor-stator structure. The $\mathrm{N}-\mathrm{H} \cdot \mathrm{O}$ hydrogen bond distances in the RTP and LTP were within the normal ranges of 2.860-2.906 and 2.846-2.924 $\AA$, respectively (Table S1). Although the LTP distance range was slightly shorter than the RTP one, the average hydrogen bond lengths were not clearly different, which suggested the absence of distinct proton transfer in $\mathrm{N}-\mathrm{H} \cdots \mathrm{O}$ hydrogen bonds. In the (3-nitroanilinium) (18-crown) supramolecular cation, the benzene ring of 3-nitroanilinium was almost perpendicular to the molecular plane of 18 -crown- 6 with dihedral angles of $87.38^{\circ}$ and $87.80^{\circ}$ observed for the LTP and RTP, respectively. Analysis of the interrelation between two adjacent (3-nitroanilinium)(18-crown) cations revealed that, besides the previously mentioned six $\mathrm{N}-\mathrm{H} \cdots \mathrm{O}$ hydrogen bonds, a seventh hydrogen bond $\left(\mathrm{N}_{1}-\mathrm{H} \cdot \mathrm{O}_{2}\right)$ passing through the cavity of 18-crown-6 
exists between the $-\mathrm{NH}_{3}{ }^{+}$group and the $-\mathrm{NO}_{2}$ group of the adjacent 3-nitroanilinium cation, linking (3-nitroanilinium)(18-crown) cations to form one-dimensional hydrogen bond chains (Figure 3, Figures S3 and S4). Further analysis showed that the distance between the donor $\left(\mathrm{N}_{1}\right)$ and acceptor atoms $\left(\mathrm{O}_{2}\right)$ is longer than that in the other six hydrogen bonds, which means that protons move more easily in one-dimensional hydrogen bond chains along the $(a+c)$-axis (in the RTP) and the $c$-axis (in the LTP) $\left[\mathrm{N}_{1}-\mathrm{H} \cdot \mathrm{O}_{2}: 3.130 \AA\right.$ at $128 \mathrm{~K} ; \mathrm{N}_{1}-\mathrm{H} \cdot \mathrm{O}: 3.144 \AA$ at $\left.296 \mathrm{~K}\right]$ (Table S1). As shown in Figure 3, the distance between two adjacent (3-nitroanilinium)(18-crown) cations was shorter in the RTP $(15.158 \AA)$ than in the LTP $(15.386 \AA)$. Hence, the concertina movement of the one-dimensional hydrogen bond chain with the change of temperature was expected to benefit proton transfer in this chain and the motion of the nitro group in the supramolecular cation. In addition, the anisotropic thermal factors of $\mathrm{O}_{1}$ exceeded those of other atoms in the 3-nitroanilinium cation, which suggested the pendulum-like motion of the nitro group in the (3-nitroanilinium) (18-crown) cation (Figure S5). The most notable difference between the two phases was observed for dihedral angles between the nitro group and the aromatic ring of the 3-nitroanilinium cation ( $15.24^{\circ}$ for LTP vs. $15.42^{\circ}$ for RTP) (Figure S6) and was ascribed to molecular interactions between the adjacent supramolecular cations in the one-dimensional hydrogen bond chain. Thus, the pendulum-like motion of the nitro group could easily occur and was possibly the driving force for the reversible phase transition in 1.

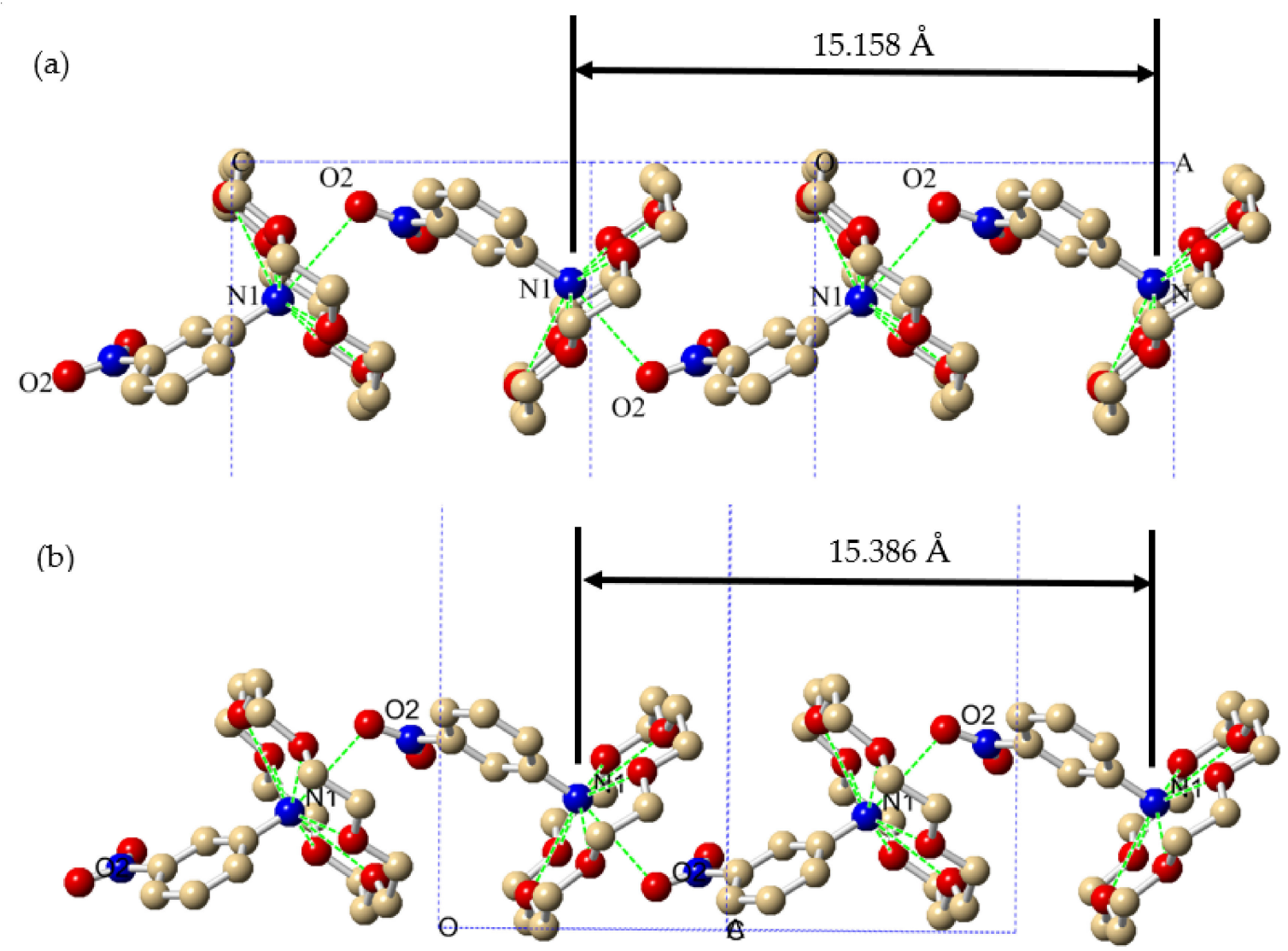

Figure 3. (a) One-dimensional hydrogen bond chains in the room-temperature phase viewed along the $a$-axis. The distance between two adjacent (3-nitroanilinium) (18-crown) cations was determined as $15.158 \AA$. (b) Hydrogen bond chains in the low-temperature phase viewed along the $(a+c)$-axis with the distance between two adjacent (3-nitroanilinium) (18-crown) cations determined as $15.386 \AA$. 
In the inorganic part of 1 , the $\mathrm{PF}_{6}{ }^{-}$anion was disordered over two staggered orientations in the RTP, but was ordered in the LTP. Further analysis showed that the $\mathrm{PF}_{6}{ }^{-}$anion, acting as a counter-ion of the supramolecular cation assembly, featured average F-P bond distances of 1.547 (LTP) and $1.567 \AA$ (RTP), i.e., no significant change in this average distance was observed during the phase transition. However, the bond angle formed by the F and P atoms in the RTP $\left(170.47^{\circ}\right)$ was lower than that in the LTP $\left(179.02^{\circ}\right.$ ) (Table S2). Structural factor analysis of $\mathrm{PF}_{6}{ }^{-}$suggests that the octahedral structure of this anion was distorted with increasing/decreasing temperature. The molecular twist at different temperatures could lead to the structural phase transition and electrical property changes along different axes. The arrangement of $\mathrm{PF}_{6}{ }^{-}$anions in the space of two one-dimensional hydrogen bond chains shows that monovalent assemblies of [(3-nitroanilinium)(18-crown) $]^{+}$and $\mathrm{PF}_{6}{ }^{-}$at a molar ratio of 1:1 were alternately stacked together along the $c$-axis in the RTP and along the $(a+c)$-axis in the LTP to build the supramolecular self-assembly structure (Figure 4).
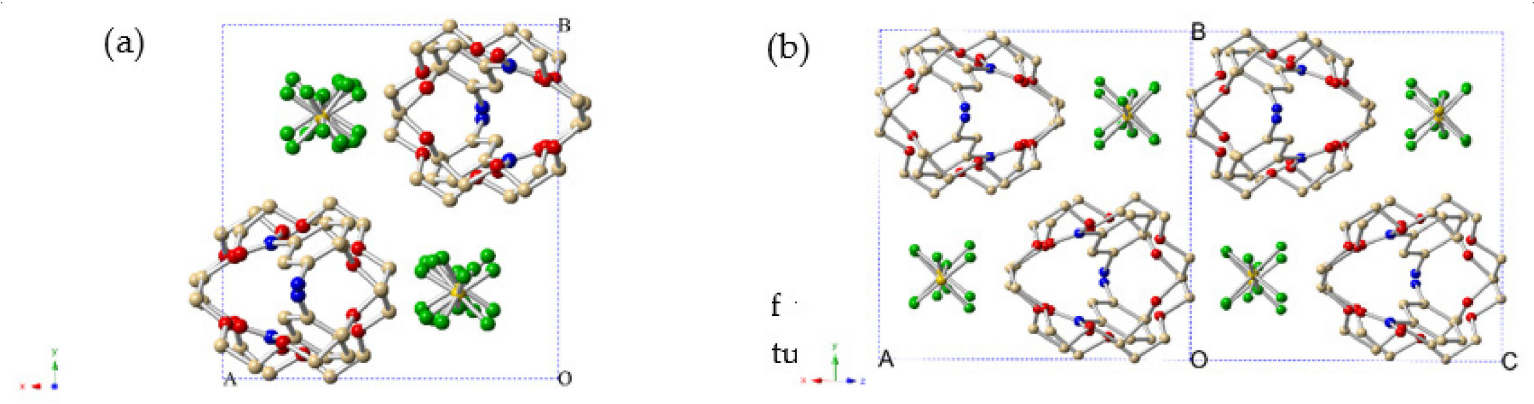

Figure 4. View of the self-assembly packing of the (3-nitroanilinium)(18-crown) cation and $\mathrm{PF}_{6}{ }^{-}$ anions (a) along the $c$-axis for the room-temperature phase and $(\mathbf{b})$ along the $(a+c)$-axis for the low-temperature phase.

\subsection{Potential Energy Calculation}

To confirm whether the molecular motions of the 3-nitroanilinium cation and the nitro group significantly contributed to the structural phase transition and abnormal electrical properties, we evaluated potential energy changes associated with the rotation of the phenyl ring and the pendulum-like motion of the nitro group in the supramolecular cation. As the $-\mathrm{NH}_{3}{ }^{+}$group of the 3-nitroanilinium cation was fixed in the cavity of 18 -crown- 6 by $\mathrm{N}-\mathrm{H} \cdot \mathrm{O}$ hydrogen bonding, the rotation of the phenyl ring occurred around the $\mathrm{C}_{18}-\mathrm{N}_{1}$ bond of the 3-nitroanilinium cation, causing the rotation of the 3-nitroanilinium dipole in the ac plane. Notably, the rotation of the 3-nitroanilinium cation was restricted by the steric hindrance of one neighboring 18-crown- 6 molecule and two $\mathrm{PF}_{6}{ }^{-}$ anions. A theoretical calculation using the RHF/6-31(d) basis set was carried out to examine the (3-nitroanilinium)(18-crown $)_{2}\left(\mathrm{PF}_{6}\right)_{2}$ model structure at $296 \mathrm{~K}$ (Figure S7a). Figure 5a presents the effects of the rotational angle $\left(\Phi=0-360^{\circ}\right.$, step $\left.=30^{\circ}\right)$ on the potential energy $(\Delta E)$ for the phenyl ring of the 3-nitroanilinium cation. The initial atomic coordinates obtained from the RTP crystal structure correspond to the first potential energy minimum at $\Phi=0^{\circ}$ of which the relative energy was defined as zero, while the second energy minimum appeared at $\Phi=180^{\circ}$. The potential energy maxima occurred at $\Phi=90^{\circ}(762.24 \mathrm{~kJ} / \mathrm{mol})$ and $270^{\circ}(1189.34 \mathrm{~kJ} / \mathrm{mol})$. The potential energy barrier of phenyl rotation in 1 was far greater than that in ( $m$-fluoroanilinium) (DB18-crown-6) [Ni(dmit) $)_{2}$, i.e., increased upon the replacement of fluorine with the nitro group [36], and suggested that phenyl ring rotation in the 3-nitroanilinium cation is unlikely to be above $296 \mathrm{~K}$. 
(a)

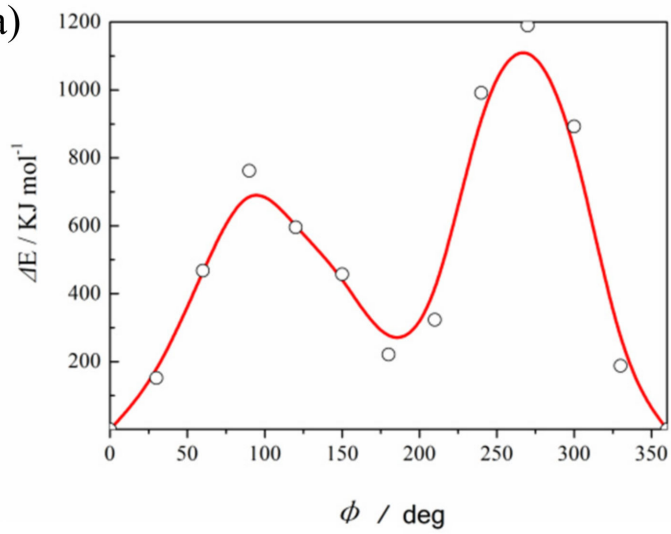

(b)

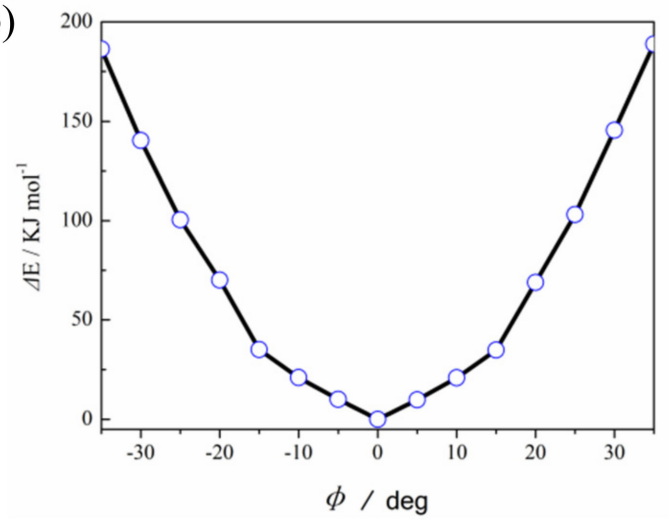

Figure 5. Potential energy curves for (a) rotational motion of the phenyl ring of the 3-nitroanilinium cation along its $\mathrm{C}-\mathrm{N}$ bond and (b) pendulum-like motion of the nitro groupin the range of $-35^{\circ}$ to $35^{\circ}$.

The pendulum-like motion of the nitro group was also evaluated for fixed atomic coordinates of the (3-nitroanilinium)(18-crown) $\left(\mathrm{PF}_{6}\right)$ model structure (Figure $\left.\mathrm{S} 7 \mathrm{~b}\right)$. Although the nitro group rotation around the $\mathrm{C}-\mathrm{N}$ bond in the $0-360^{\circ}$ range is unlikely because of the large steric hindrance of neighboring 18-crown- 6 and $\mathrm{PF}_{6}{ }^{-}$units, we calculated symmetrical potential energy profiles for this pendulum-like motion at $5^{\circ}$ increments within the range of $-35^{\circ}$ to $35^{\circ}$ (Figure $5 \mathrm{~b}$ ). The maximum $\Delta E$ of $180 \mathrm{~kJ} / \mathrm{mol}(<270 \mathrm{~kJ} / \mathrm{mol})$ indicated that the pendulum-like motion of the nitro group around the $\mathrm{C}_{14}-\mathrm{N}_{2}$ bond is possible at $296 \mathrm{~K}$ and can, therefore, affect the phase transition and electrical property changes.

\subsection{Dielectric Properties}

The frequency-dependent dielectric response at different temperatures can be used to detect thermally activated molecular motion and structural changes, e.g., when the change of polarity due to molecular motion or order-disorder change in the crystal is of the order of the measurement frequency. Clear dielectric responses are expected. With increasing temperature, the molecular motion of the disordered $\mathrm{PF}_{6}{ }^{-}$anion in the molecular rotor was severely restricted, as higher temperatures favored the more disordered RTP and were expected to induce a change of molecular polarity due to order-disorder motion. The potential energy curve of the nitro-group pendulum motion is very shallow, and the dielectric response for this motion should be large. Therefore, the pendulum motion of the nitro group associated with order-disorder anion motion significantly affects the dipole moment of which the response should be mainly observed by monitoring temperature-dependent and frequency-dependent dielectric properties.

Given the difficulty of obtaining large crystals of $\mathbf{1}$, pressed powders comprising plate-shaped particles were used for dielectric measurements. The dielectric constant $\left(\varepsilon^{\prime}\right)$ of $\mathbf{1}$ was monitored in the range of $100-300 \mathrm{~K}$ at frequencies of $0.5,1,5,10,100$, and $1000 \mathrm{kHz}$ (Figure 6). A sharp dielectric phase transition peak (dielectric anomaly) was observed around $221.75 \mathrm{~K}$ upon cooling, which is in line with the phase transition observed at $223.7 \mathrm{~K}$. Dielectric constants at temperatures below $190 \mathrm{~K}$ exhibited temperature-dependent and frequency-dependent behavior with a constant $\varepsilon^{\prime}$ of 14.2 , whereas a large dielectric constant enhancement was observed above $190 \mathrm{~K}$ and below $10 \mathrm{kHz}$. The dielectric constant ( 50) obtained at $500 \mathrm{~Hz}$ and $221.75 \mathrm{~K}$ was four times larger than that obtained at $500 \mathrm{~Hz}$ and $100 \mathrm{~K}$. This low-frequency response suggests a relatively slow pendulum-like motion of the nitro group rather than fast electronic motion, possibly reflecting the fact that the 3-nitroanilinium cation and the $\mathrm{PF}_{6}{ }^{-}$anion are present in orientationally ordered states at low temperature. Above $200 \mathrm{~K}$, the pendulum motion of the nitro group and the order-disorder motion of $\mathrm{PF}_{6}{ }^{-}$were coupled to yield a strong dipole moment component and, thus, increase the dielectric constant. In addition, the dielectric loss constant $\left(\varepsilon^{\prime \prime}\right)$ also displays a sharp change and remarkable frequency-dependent 
phenomenon at selected frequencies. The anomalies of $\varepsilon^{\prime}$ and $\varepsilon^{\prime \prime}$ strongly confirm the existence of phase transitions of $\mathbf{1}$, which is consistent with the results of DSC and structural analysis. Thus, the crystal structures of $\mathbf{1}$ at low and room temperatures indicate that the pendulum motion of the nitro group and the order-disorder motion of $\mathrm{PF}_{6}{ }^{-}$may be the driving force of the LTP $\rightarrow \mathrm{RTP}$ phase transition and anomalous dielectric behavior.

(a)

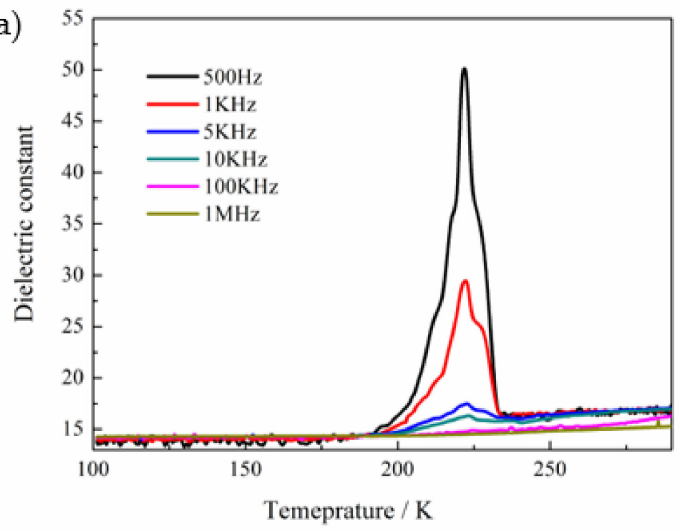

(b)

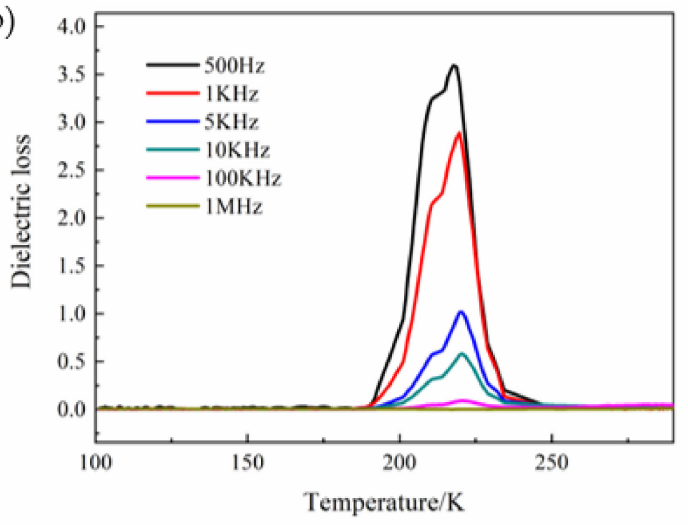

Figure 6. (a) Real part $\left(\varepsilon^{\prime}\right)$ and (b) imaginary $\left(\varepsilon^{\prime \prime}\right)$ of permittivity on the dielectric response of $\mathbf{1}$ measured at $500 \mathrm{~Hz}-1 \mathrm{MHz}$ obtained on heating and cooling.

\section{Materials and Methods}

\subsection{Materials and Measurements}

All reagents and solvents used for the synthesis of $\mathbf{1}$ were purchased from TCI (Tokyo Chemical Industry, Shanghai, China) and were of an analytical grade and used without further purification. IR spectra were recorded on an Affinity-1 spectrophotometer (400-4000 cm-1$)$. Elemental analyses were carried out using a Vario EL instrument (Elementar Analysensysteme GmbH) at the TRW research Collaboration Center. DSC experiments were performed on a TA Q2000 instrument by heating and cooling crystalline samples $(7.5 \mathrm{mg})$ under nitrogen at a rate of $5 \mathrm{~K} / \mathrm{min}$. TG analysis was carried out on a TA Q50 instrument in a flow of nitrogen at a heating rate of $10 \mathrm{~K} / \mathrm{min}$. The temperature-dependent dielectric constants of $\mathbf{1}$ along the three axis directions were measured using a Tonghui 2828 impedance analyzer in the frequency range of $500 \mathrm{~Hz}-1 \mathrm{MHz}$ using an applied electric field of $0.5 \mathrm{~V}$. The powder-pressed and single-crystal pellets were then sandwiched between two parallel copper electrodes by the carbon paste for dielectric measurements.

\subsection{Preparation of (3-Nitroanilinium)(18-Crown-6)( $\left.P F_{6}\right)(1)$}

3-Nitroaniline (104.5 mg, $0.75 \mathrm{mmol})$ was dissolved in methanol $(10 \mathrm{~mL})$, and a solution of $\mathrm{HPF}_{6}$ (273.6 $\mathrm{mg}$ ) in water $(410 \mathrm{mg}$ ) was added dropwise to the obtained mixture under stirring. Subsequently, the acidic solution was mixed with a solution of 18-crown-6 (200 mg, $0.75 \mathrm{mmol})$ in methanol (10 mL) (Scheme 1). Slow evaporation of methanol from the obtained solution at room temperature yielded large colorless crystals (up to $0.8 \mathrm{~cm} \times 1.0 \mathrm{~cm} \times 1.2 \mathrm{~cm}$ ) of $\mathbf{1}$ (yield $=67 \%$, m.p. $=120-130{ }^{\circ} \mathrm{C}$ ) after about one week. The composition of 1 was determined by elemental and X-ray crystallographic analyses. Anal. Calcd. $\mathrm{C}_{18} \mathrm{H}_{31} \mathrm{~F}_{6} \mathrm{~N}_{2} \mathrm{O}_{8} \mathrm{P}$ for 1: C: $39.42 \%, \mathrm{H}: 5.70 \%, \mathrm{~N}: 5.11 \%$. Found: C: $39.31 \%, \mathrm{H}: 5.40 \%$, N: $5.02 \%$. 


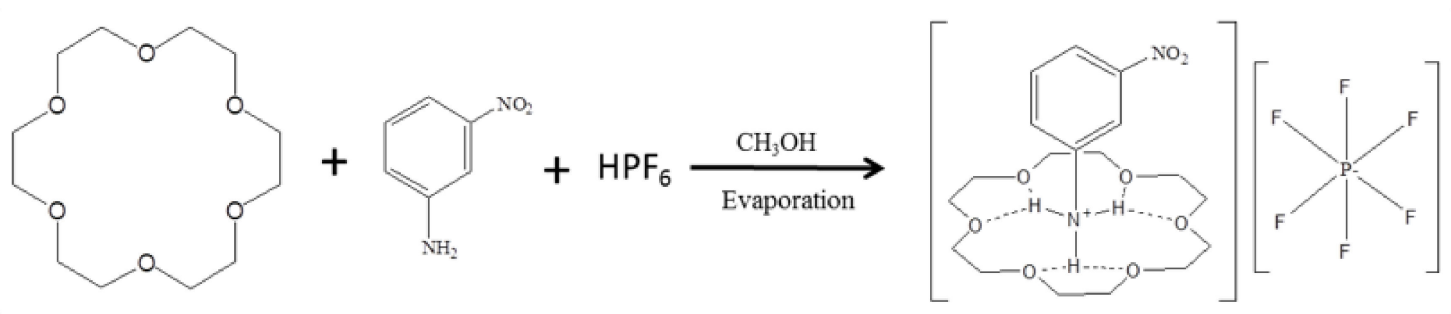

Scheme 1. Synthesis of 1 .

\subsection{Single-Crystal X-ray Diffraction Measurements}

Variable-temperature (128 and 296 K) X-ray single-crystal diffraction measurements were carried out for the same crystal on a Rigaku Saturn 924 diffractometer equipped with a Rigaku low-temperature gas-spray cooler using Mo $K_{\alpha}$ radiation $(\lambda=0.71073 \AA)$. Data collection, cell refinement, and data reduction were performed using Rigaku Crystal Clear 1.3.5 software. The structure of 1 was solved by direct methods and refined by the full-matrix method based on $F^{2}$ using the SHELXL97 software package. All non-hydrogen atoms were refined anisotropically, and the positions of all hydrogen atoms were generated geometrically. Supplementary crystallographic data for $\mathbf{1}$ were deposited at the Cambridge Crystallographic Data Centre (CCDC, Nos. 1,997,720 (128 K) and 1,997,721 (293 K) and can be obtained free of change at www.ccdc.cam.ac.uk/data_request/cif.

\subsection{Calculation of Rotational Potential Energy}

The relative energies of crystal structures were calculated based on a semi-empirical method using the RHF/6-31(d) basis set [37]. Calculations of the rotation potential energy of the 3-nitroanilinium phenyl ring were performed including the nearest-neighbor molecules around this ring and using the atomic coordinates of 1 determined by a low-temperature $\mathrm{X}$-ray crystal structure analysis. The structural units of $\mathbf{1}$ used in the calculation were (3-nitroanilinium) (18-crown $)_{2}\left(\mathrm{PF}_{6}\right)_{2}$ (Figure S7). The relative energies of different structures were obtained by evaluating the rigid rotation of the phenyl ring around the $\mathrm{C}_{18}-\mathrm{N}_{1}$ bond (Figure S7a). Rotation was performed in $30^{\circ}$ steps in the range of $0-360^{\circ}$. Calculations of the rotational potential energy of the nitro group were performed by including the nearest-neighbor molecules around the nitro group (Figure S7b). The relative energies of different structures were obtained by evaluating the rigid rotation (in $5^{\circ}$ steps in the range of $-35^{\circ}$ to $30^{\circ}$ ) of the nitro group around the $\mathrm{C}_{14}-\mathrm{N}_{2}$ bond.

\section{Conclusions}

Compound 1 underwent a reversible structural phase transition at $\sim 223 \mathrm{~K}$ (from the space group $P 2_{1} /$ n at a low temperature to $P 2_{1} / \mathrm{c}$ at room temperature). Potential energy calculations of the nitro group revealed the important role of pendulum-like motion for a physical performance change. The combined results of DSC, single-crystal X-ray diffraction, and dielectric constant measurements revealed that a synergistic effect between the pendulum-like motion of the nitro group and the order-disorder motion of $\mathrm{PF}_{6}{ }^{-}$gives rise to the above phase transition and a sharp dielectric anomaly peak.

Supplementary Materials: The following are available online at http://www.mdpi.com/2073-4352/10/11/1028/s1, Figure S1. IR spectrum of compound 1. Figure S2. TG and DTA curves for compound 1. Figure S3. The self-assembly packing of 18-crown-6 and 3-nitroanilinium along the c-axis. Figure S4. One dimensional N-H-O hydrogen bond chain structure. Figure S5. View of 3-nitroanilinium cation of compound 1. Figure S6. Dihedral angle of benzene and -NO2 group of the super-molecular cation. Figure S7. Model structure of compound 1 for the potential energy calculations. Table S1. Hydrogen-bond geometry $\left(\AA^{\circ}\right)$ for complex 1 . Table S2. Selected bond distances and angles for compound $1\left(\AA^{\circ}\right)$. 
Author Contributions: Z.-q.L. designed the method and wrote the manuscript. L.W. synthesized the crystalline materials. Y.L. and L.-1.Q. supported the dielectric constant and DSC measurements. P.W. and H.-t.X. analyzed the crystal data of 1 . All authors have read and agreed to the published version of the manuscript.

Funding: The present work was supported by the National Natural Science Foundation of China (no. 21561030), Xinjiang Uygur Autonomous Region Postgraduate Scientific Research Innovation Project (XJ2020G162), and the "1000 Talent Plan" on Overseas High-Level Talents Introduction (CCCPC)

Conflicts of Interest: The authors declare no conflict of interest.

\section{References}

1. Wang, X.-L.; Zhou, L.; Ye, Q.; Geng, F.-J.; Ye, H.-Y.; Fu, D.-W.; Zhang, Y. A spiro-type ammonium based switchable dielectric material with two sequential reversible phase transitions above room temperature. RSC Adv. 2016, 6, 74117-74123. [CrossRef]

2. Zhang, W.; Xiong, R.-G. Ferroelectric Metal-Organic Frameworks. Chem. Rev. 2012, 112, $1163-1195$. [CrossRef] [PubMed]

3. You, Y.-M.; Liao, W.; Zhao, D.; Ye, H.-Y.; Zhang, Y.; Zhou, Q.; Niu, X.; Wang, J.; Li, P.; Fu, D.-W.; et al. An organic-inorganic perovskite ferroelectric with large piezoelectric response. Science 2017, 357, 306-309. [CrossRef] [PubMed]

4. $\quad$ Liao, W.-Q.; Tang, Y.-Y.; Li, P.-F.; You, Y.-M.; Xiong, R.-G. Competitive Halogen Bond in the Molecular Ferroelectric with Large Piezoelectric Response. J. Am. Chem. Soc. 2018, 140, 3975-3980. [CrossRef] [PubMed]

5. Zhang, W.Y.; Tang, Y.Y.; Li, P.-F.; Shi, P.P.; Liao, W.Q.; Fu, D.W.; Ye, H.Y.; Zhang, Y.; Xiong, R.G. Precise Molecular Design of High-T c 3D Organic-Inorganic Perovskite Ferroelectric: [MeHdabco] RbI3 $($ MeHdabco $=$ N-Methyl-1, 4-diazoniabicyclo [2.2.2] octane). J. Am. Chem. Soc. 2017, 139, 10897-10902. [CrossRef]

6. Zhang, Z.-X.; Zhang, T.; Shi, P.-P.; Zhang, W.-Y.; Ye, Q.; Fu, D.-W. Anion-Regulated Molecular Rotor Crystal: The First Case of a Stator-Rotator Double Switch with Relaxation Behavior. J. Phys. Chem. Lett. 2019, 10, 4237-4244. [CrossRef] [PubMed]

7. Liao, W.-Q.; Zhang, Y.; Hu, C.-L.; Mao, J.-G.; Ye, H.-Y.; Li, P.-F.; Huang, S.D.; Xiong, R.-G. A lead-halide perovskite molecular ferroelectric semiconductor. Nat. Commun. 2015, 6, 7338. [CrossRef]

8. Wang, Z.-X.; Liao, W.-Q.; Ye, H.; Zhang, Y. Sequential structural transitions with distinct dielectric responses in a layered perovskite organic-inorganic hybrid material: $\left[\mathrm{C}_{4} \mathrm{H}_{9} \mathrm{~N}_{2}\left[\mathrm{PbBr}_{4}\right]\right.$. Dalton Trans. 2015, 44, 20406-20412. [CrossRef]

9. Zhang, W.-Y.; Ye, Q.; Fu, D.-W.; Xiong, R.-G. Optoelectronic Duple Bistable Switches: A Bulk Molecular Single Crystal and Unidirectional Ultraflexible Thin Film Based on Imidazolium Fluorochromate. Adv. Funct. Mater. 2016, 27, 27-1603945. [CrossRef]

10. Zhang, Z.-X.; Zhang, T.; Shi, P.-P.; Zhang, W.-Y.; Ye, Q.; Fu, D.-W. Exploring high-performance integration in a plastic crystal/film with switching and semiconducting behavior. Inorg. Chem. Front. 2020, 7, 1239-1249. [CrossRef]

11. Pan, Q.; Liu, Z.-B.; Tang, Y.-Y.; Li, P.; Ma, R.-W.; Wei, R.-Y.; Zhang, Y.; You, Y.-M.; Ye, H.; Xiong, R.-G. A Three-Dimensional Molecular Perovskite Ferroelectric: (3-Ammoniopyrrolidinium)RbBr3. J. Am. Chem. Soc. 2017, 139, 3954-3957. [CrossRef]

12. Tang, Y.-Z.; Yu, Y.-M.; Xiong, J.-B.; Tan, Y.-H.; Wen, H.-R. Unusual High-Temperature Reversible Phase-Transition Behavior, Structures, and Dielectric-Ferroelectric Properties of Two New Crown Ether Clathrates. J. Am. Chem. Soc. 2015, 137, 13345-13351. [CrossRef] [PubMed]

13. Liu, S.; Li, J.; Sun, Z.; Ji, C.; Li, L.; Zhao, S.; Luo, J. Order-Disorder Phase Transition, Anisotropic and Switchable Dielectric Constants Induced by Freeze of the Wheel-Like Motion in a Hexafluorosilicate-Based Crystal. Chemistry 2016, 1, 5310-5315. [CrossRef]

14. Zhang, H.-Y.; Song, X.-J.; Cheng, H.; Zeng, Y.-L.; Zhang, Y.; Li, P.-F.; Liao, W.-Q.; Xiong, R.-G. A Three-Dimensional Lead Halide Perovskite-Related Ferroelectric. J. Am. Chem. Soc. 2020, 142, 4604-4608. [CrossRef]

15. Chen, L.-Z.; Cao, X.-X. Two novel phase transition materials based on 1-isopropyl-1,4-diazabicyclo [2.2.2]octan-1-ium. Chin. Chem. Lett. 2017, 28, 400-406. [CrossRef] 


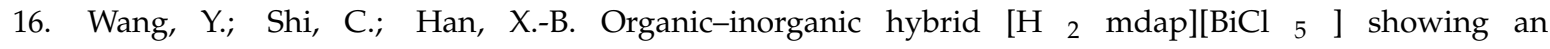
above-room-temperature ferroelectric transition with combined order-disorder and displacive origins. Polyhedron 2017, 133, 132-136. [CrossRef]

17. Han, X.-B.; Hu, P.; Shi, C.; Zhang, W. Structural phase transitions and dielectric transitions in a 1,4-diazabicyclo[2.2.2] octane (dabco) based organic crystal. J. Mol. Struct. 2017, 1127, 372-376. [CrossRef]

18. Liu, Y.-L.; Ge, J.-Z.; Wang, Z.-X.; Xiong, R.-G. Metal-organic ferroelectric complexes: Enantiomer directional induction achieved above-room-temperature homochiral molecular ferroelectrics. Inorg. Chem. Front. 2020, 7, 128-133. [CrossRef]

19. Xu, W.-J.; Chen, S.-L.; Hu, Z.-T.; Lin, R.-B.; Su, Y.-J.; Zhang, W.-X.; Chen, X.-M. The cation-dependent structural phase transition and dielectric response in a family of cyano-bridged perovskite-like coordination polymers. Dalton Trans. 2016, 45, 4224-4229. [CrossRef] [PubMed]

20. Li, X.-N.; Li, P.; Wang, Z.-X.; Shi, P.-P.; Tang, Y.-Y.; Ye, H.-Y. The structural phase transition in a hybrid layered perovskite: [C7H16N]2[SnI4]. Polyhedron 2017, 129, 92-96. [CrossRef]

21. Tang, Y.-Z.; Gu, Z.-F.; Xiong, J.-B.; Gao, J.-X.; Liu, Y.; Wang, B.; Tan, Y.-H.; Xu, Q. Unusual Sequential Reversible Phase Transitions Containing Switchable Dielectric Behaviors in Cyclopentyl Ammonium 18-Crown-6 Perchlorate. Chem. Mater. 2016, 28, 4476-4482. [CrossRef]

22. Ye, H.-Y.; Li, S.-H.; Zhang, Y.; Zhou, L.; Deng, F.; Xiong, R.-G. Solid State Molecular Dynamic Investigation of An Inclusion Ferroelectric: [(2,6-Diisopropylanilinium)([18]crown-6)]BF4. J. Am. Chem. Soc. 2014, 136, 10033-10040. [CrossRef] [PubMed]

23. Ye, H.-Y.; Ge, J.-Z.; Tang, Y.-Y.; Li, P.; Zhang, Y.; You, Y.-M.; Xiong, R.-G. Molecular Ferroelectric with Most Equivalent Polarization Directions Induced by the Plastic Phase Transition. J. Am. Chem. Soc. 2016, 138, 13175-13178. [CrossRef]

24. Zhang, X.; Shao, X.-D.; Li, S.-C.; Cai, Y.; Yao, Y.; Xiong, R.-G.; Zhang, W. Dynamics of a caged imidazolium cation-toward understanding the order-disorder phase transition and the switchable dielectric constant. Chem. Commun. 2015, 51, 4568-4571. [CrossRef]

25. Liu, Z.-Q.; Kubo, K.; Noro, S.-I.; Akutagawa, T.; Nakamura, T. Design of Crystalline Spaces for Molecular Rotations in Crystals. Cryst. Growth Des. 2013, 14, 537-543. [CrossRef]

26. Liao, W.Q.; Ye, H.Y.; Fu, D.W.; Li, P.F.; Chen, L.Z.; Zhang, Y. Temperature-T;riggered Reversible Dielectric and Nonlinear Optical Switch Based on the One-Dimensional Organic-Inorganic Hybrid Phase Transition Compound $\left[\mathrm{C}_{6} \mathrm{H}_{11} \mathrm{NH}_{3}\right]_{2} \mathrm{CdCl}_{4}$. Inorg. Chem. 2014, 53, 11146-11151. [CrossRef]

27. Ye, Q.; Shi, P.-P.; Chen, Z.-Q.; Akutagawa, T.; Noro, S.-I.; Nakamura, T. Flexible cis-Cyclohexane-1,4-diammonium Ion in Magnetic [Ni(dmit)2] Crystals. Eur. J. Inorg. Chem. 2012, 2012, 3732-3739. [CrossRef]

28. Xu, G.; Chen, C.-H.; Zhang, L. Switchable dielectric behavior induced by a disorder-order structural phase transition in $\left(\mathrm{C}_{3} \mathrm{H}_{12} \mathrm{~N}_{2}\right)_{2}\left(\mathrm{HSO}_{4}\right)_{2}\left[\mathrm{Mn}\left(\mathrm{H}_{2} \mathrm{O}\right)_{4}\left(\mathrm{SO}_{4}\right)_{2}\right.$ ]. Polyhedron 2016, 117, 133-137. [CrossRef]

29. Ye, Q.; Akutagawa, T.; Ye, H.Y.; Hang, T.; Ge, J.Z.; Xiong, R.G.; Noro, S.I.; Nakamura, T. Structural phase transition due to the flexible supramolecule of (4-cyanomethylanilinium)([18] crown-6) in [Ni (dmit) 2$]-$ crystal. Cryst. Eng. Comm. 2011, 13, 6185-6191. [CrossRef]

30. Liu, Y.; Chen, Y.; Xu, M.-J.; Zhu, C.-L.; Liu, Z.-Q. Synthesis, structure, and phase transition of a novel proton transfer in a supramolecular cation with 2-nitroanilinium based on 18-crown-6. J. Mol. Struct. 2017, 1148, 429-434. [CrossRef]

31. Hoshino, N.; Yoshii, Y.; Aonuma, M.; Kubo, K.; Nakamura, T.; Akutagawa, T. Supramolecular Rotators of (Aniliniums)([18]crown-6) in Electrically Conducting [Ni(dmit)2] Crystals. Inorg. Chem. 2012, 51, 12968-12975. [CrossRef] [PubMed]

32. Ohshima, Y.; Kubo, K.; Matsumoto, T.; Ye, H.-Y.; Noro, S.-I.; Akutagawa, T.; Nakamura, T. One-dimensional supramolecular columnar structure of trans-syn-trans-dicyclohexano[18]crown-6 and organic ammonium cations. Cryst. Eng. Comm. 2016, 18, 7959-7964. [CrossRef]

33. Zhou, P.; Sun, Z.; Zhang, S.; Chen, T.; Ji, C.; Zhao, S.; Luo, J. Switchable Dielectric Phase Transition Induced by a Twisting Transformation in Diglycine Methanesulfonate. Chem. Asian J. 2014, 9, 996-1000. [CrossRef]

34. Li, S.; Luo, J.; Sun, Z.; Zhang, S.; Li, L.; Shi, X.; Hong, M. Phase Transition Triggered by Ordering of Unique Pendulum-Like Motions in a Supramolecular Complex: Potassium Hydrogen Bis(dichloroacetate)-18-Crown-6. Cryst. Growth Des. 2013, 13, 2675-2679. [CrossRef] 
35. Liu, Z.; Liu, Y.; Chen, Y.; Zhao, W.-Q.; Fang, W.-N. Synthesis, characterization, and phase transition of an inorganic-organic hybrid compound, [(3-nitroanilinium +$)(18-c r o w n-6)]\left[\mathrm{IO}_{4}{ }^{-}\right]\left(\mathrm{CH}_{3} \mathrm{OH}\right)$. Chin. Chem. Lett. 2017, 28, 297-301. [CrossRef]

36. Akutagawa, T.; Koshinaka, H.; Sato, D.; Takeda, S.; Noro, S.-I.; Takahashi, H.; Kumai, R.; Tokura, Y.; Nakamura, T. Ferroelectricity and polarity control in solid-state flip-flop supramolecular rotators. Nat. Mater. 2009, 8, 342-347. [CrossRef]

37. Frisch, M.J.; Trucks, G.W.; Schlegel, H.B.; Scuseria, G.E.; Robb, M.A.; Cheeseman, J.R.; Montgomery, Jr.; Vreven, J.A.T.; Kudin, K.N.; Burant, J.C.J.; et al. People, Gaussian 03, Revision C.02; Gaussian Inc.: Wallingford, CT, USA, 2004.

Publisher's Note: MDPI stays neutral with regard to jurisdictional claims in published maps and institutional affiliations.

(C) 2020 by the authors. Licensee MDPI, Basel, Switzerland. This article is an open access article distributed under the terms and conditions of the Creative Commons Attribution (CC BY) license (http://creativecommons.org/licenses/by/4.0/). 